J. Great Lakes Res. 15(2):233-245

Internat. Assoc. Great Lakes Res., 1989

\title{
INFLUENCE OF LAKE SURFACE AREA AND DEPTH UPON THERMAL STRATIFICATION AND THE DEPTH OF THE SUMMER THERMOCLINE
}

\author{
Eville Gorham \\ Department of Ecology and Behavioural Biology \\ University of Minnesota \\ Minneapolis, Minnesota 55455 \\ Farrell M. Boyce \\ Lakes Research Branch \\ National Water Research Institute \\ Canada Centre for Inland Waters \\ Burlington, Ontario L7R $4 A 6$
}

\begin{abstract}
Among the important physical characteristics of a lake are whether it stratifies seasonally, and if so, the depth to which wind-mixing is limited by the stratification. It is generally known that sufficiently shallow lakes tend to remain isothermal throughout the year and that the depth of the thermocline in stratified lakes correlates positively with the surface area of the lake. Observations from lakes in several different regions of the temperate zone of the northern hemisphere show that whether a lake stratifies depends on both the maximum depth and the surface area of the lake, whereas the depth of the thermocline depends primarily on the surface area. A modification of previously published scaling arguments provides a plausible theoretical basis for some of this behavior. These arguments account for additional shear-induced mixing associated with the fundamental internal seiche in small lakes and with near-inertial motion in big lakes. For lakes of crossbasin diameter less than $5,000 \mathrm{~m}$ (surface area less than $25 \mathrm{~km}^{2}$ ), an estimate of the depth of the thermocline, $h$, at the time of maximum heat content is given by:
\end{abstract}

$$
\mathrm{h} \equiv 2.0\left(\frac{\tau}{\mathrm{g} \Delta \rho}\right)^{1 / 2} \mathrm{~L}^{1 / 2}
$$

where $\tau$ is the wind stress associated with late summer storms, $\Delta p$ is the density contrast between epilimnion and hypolimnion typical for lakes in that region near the time of maximum heat content, $g$ is the gravitational acceleration, and $L$ is the square root of the surface area of the lake. A consistent set of units must be employed.

ADDITIONAL INDEX WORDS: Dimensional analysis, wind-induced mixing, buoyancy, Coriolis force.

\section{INTRODUCTION}

Probably the most important physical characteristics of a lake are whether it stratifies seasonally, and if so, the depth to which surface mixing is limited by stratification. Stratification influences the utilization of nutrients supplied to the lake by external loadings, the nature of the habitat for organisms, and the ability of the lake to store heat and to modify the local climate.

Like the annual heat budget (Gorham 1964), stratification and the depth of mixing are obvi- ously influenced by geometric factors such as surface area and maximum depth. Yet the limnological textbooks do not deal with these relationships quantitatively. Gorham (1958) attempted to assess them when examining the physical limnology of the Scottish lochs, but the data allowed only the establishment of general relationships between surface and bottom temperature and lake area and depth. In perusing the literature since that time, only a few papers have been found dealing briefly with such relationships (Horiuchi 1959; Arai 1964, 1981; Patalas 1984; Ragotzkie 1978). According to 
Arai, thermocline depth $(\mathrm{m})$ in Japanese lakes is approximately 6 times the cube root of fetch $(\mathrm{km}$, determined as the square root of area). Patalas observed that the epilimnion depth (m) in Polish lakes is 3.1 times the square root of the sum of maximum length and maximum breadth $(\mathrm{km})$. Ragotzkie stated that the thermocline depth (m) is equal to 4 times the square root of the maximum unobstructed fetch $(\mathrm{km})$.

Such relationships deserve further consideration, notably an assessment of geometric controls upon thermocline depth. It is also important to determine - for a lake of a given area - the depth that it must attain in order to remain consistently stratified in summer. Lathrop and Lillie (1980) suggested that the maximum depth in meters must exceed 3.8 times the $\log 10$ of a lake's area in hectares before it will stratify. Moreover, it is unsatisfactory to define these relationships only by means of empirical curve-fitting when ultimately they must depend on physical processes for which there is a plethora of theories and models.

The present study was initiated by E. Gorham, who gathered most of the data and performed the early empirical analyses. The scaling arguments linking the climatological data with simple physical theories of mixed layer formation were provided by F. Boyce; they are based largely on a paper by Spigel and Imberger (1980), known hereafter as SI.

\section{METHODS}

Fifty-four Minnesota lakes, both stratified and unstratified, were studied for 1 to 4 years (1973, $1974,1976,1979)$ from the last week of July to the third week of August. They were selected to show the greatest possible variation in depth over the full range of lake area. Lake dimensions were taken from bathymetric maps made by the Minnesota Department of Natural Resources. All of the lakes were located within $100 \mathrm{~km}$ of the University of Minnesota's field biology station in Itasca State Park in northwestern Minnesota $\left(47^{\circ} 14^{\prime} \mathrm{N}\right.$ by $\left.95^{\circ} 11^{\prime} \mathrm{W}\right)$.

Temperature profiles were taken with a thermistor probe near the deepest point in each lake, and several measurements within the metalimnion of the stratified lakes allowed precise calculation of the depth of the thermocline-taken as the plane of the maximum rate of decrease in temperature (Hutchinson 1957). For practical purposes this surface will be close to the level of maximum density gradient. In a number of lakes the temperature profile was too irregular to locate the thermocline accurately. In the few cases where double thermoclines were obvious, the deeper one was used for all calculations. The 20 Minnesota lakes with unambiguous temperature profiles were selected for subsequent calculations of thermocline depth. Data from the lakes in northwestern Ontario, the Finger Lakes, and the lakes in England for the same JulyAugust period were treated in a similar fashion.

Data from Japanese lakes and British Columbia coastal lakes contained an estimate of thermocline depth only. The information from lakes in Poland consisted of a depth to the bottom of the epilimnion and a depth to the top of the hypolimnion; these were averaged to yield an estimate of thermocline depth. Temperature profiles were available for the British Columbia interior lakes and the Colorado lakes, whereas isotherm plots of the seasonal thermal structure were available for the Muskoka lakes. Thermocline depths for these last lakes could then be determined for the time closest to maximum heat content in a fashion similar to that employed for the Minnesota lakes. The variety of procedures used to estimate thermocline depth has introduced additional uncertainty to the results. The question of an objective determination of thermocline depth, given a detailed knowledge of the temperature profile has been recently reviewed by LeBlond and Orvig (1982). It should be emphasized that the thermocline depth referred to in the balance of this paper (designated by the symbol $h$ ) is assumed to be that occurring at or near the time of maximum heat content of the lake.

\section{RESULTS}

Table 1 gives the locations and ranges of dimensions for the groups of consistently stratified lakes that have been studied. In order to keep the dimensions as simple as possible, we have chosen as a primary independent variable the square root of the lake surface area expressed in meters (L), and described as cross-basin length or simply length. The second independent variable is the maximum depth of the lake $(H)$. Length and depth are not independent of one another (Fig. 1) Typical epilimnion and hypolimnion temperatures are also reported in Table 1 as well as the relevant dynamic variable derived from them, the reduced gravity,

$$
\mathrm{g}^{\prime}=\mathrm{g}\left(\frac{\rho \mathrm{h}-\rho \mathrm{e}}{\rho \mathrm{h}}\right)
$$


TABLE 1. Characteristics of the data collections. A single entry in a compartment is a mean or typical value for the region. Two entries define the range of the observed values. Alt. refers to the altitude of the lakes above sea level. $h$ is the depth of thermocline at or near the time of maximum heat content. $\theta_{F}$ and $\theta_{H}$ are surface and bottom temperatures at this time (Japanese temperatures are from Yoshimura, 1936). $g^{\prime}$ is the reduced gravity (defined in the text).

\begin{tabular}{|c|c|c|c|c|c|c|c|c|c|c|c|}
\hline Collection & $\begin{array}{l}\text { No. of } \\
\text { Lakes }\end{array}$ & Lat. & Long. & $\begin{array}{l}\text { Alt. } \\
(\mathrm{m})\end{array}$ & $\begin{array}{l}\text { Area } \\
\text { (ha) }\end{array}$ & $\begin{array}{l}\text { Length } \\
\text { (m) }\end{array}$ & $\begin{array}{l}\text { Maximum } \\
\text { Depth } \\
\text { (m) }\end{array}$ & $\begin{array}{c}\mathrm{h} \\
(\mathrm{m})\end{array}$ & $\begin{array}{c}\theta \mathrm{E} \\
\left({ }^{\circ} \mathrm{C}\right)\end{array}$ & $\begin{array}{c}\theta \mathrm{H} \\
\left({ }^{\circ} \mathrm{C}\right)\end{array}$ & $\begin{array}{c}\mathrm{g}^{\prime} \\
\left(\mathrm{ms}^{-2}\right)\end{array}$ \\
\hline Minne & 20 & $47^{\circ} \mathrm{N}$ & $5^{\circ} \mathrm{W}$ & $\begin{array}{l}400 \\
450\end{array}$ & $\begin{array}{r}1.8 \\
2,085\end{array}$ & $\begin{array}{r}134 \\
4,566\end{array}$ & $\begin{array}{r}6.4 \\
64.9\end{array}$ & $\begin{array}{r}2.6 \\
17.0\end{array}$ & $\begin{array}{l}21.7 \\
28.0\end{array}$ & $\begin{array}{r}4.0 \\
12.2\end{array}$ & $\begin{array}{l}0.020 \\
0.034\end{array}$ \\
\hline NW Ontario & 17 & $50^{\circ} \mathrm{N}$ & $94^{\circ} \mathrm{W}$ & 370 & 1.7 & 130 & $\begin{array}{l}4.2 \\
167\end{array}$ & 1.9 & 18.5 & 4.4 & 0.015 \\
\hline S Ontario & 16 & $45^{\circ} \mathrm{N}$ & $78^{\circ} \mathrm{W}$ & 275 & $\begin{array}{r}11 \\
124\end{array}$ & $\begin{array}{r}332 \\
1,113\end{array}$ & $\begin{array}{l}12 \\
40\end{array}$ & $\begin{array}{r}5.5 \\
10.1\end{array}$ & $\begin{array}{l}19.0 \\
22.0\end{array}$ & $\begin{array}{l}5.0 \\
6.5\end{array}$ & $\begin{array}{l}0.014 \\
0.020\end{array}$ \\
\hline Finger Lakes, N.Y. & 9 & $42^{\circ} \mathrm{N}$ & $77^{\circ} \mathrm{W}$ & $\begin{array}{l}116 \\
333\end{array}$ & $\begin{array}{r}259 \\
17,540\end{array}$ & $\begin{array}{r}1,6 \\
13,2\end{array}$ & $\begin{array}{r}18 \\
188\end{array}$ & $\begin{array}{r}7.3 \\
16.0\end{array}$ & $\begin{array}{l}21.9 \\
23.8\end{array}$ & $\begin{array}{r}4.3 \\
10.0\end{array}$ & $\begin{array}{l}0.021 \\
0.023\end{array}$ \\
\hline Great Lakes & 4 & $\begin{array}{l}41^{\circ} \mathrm{N} \\
49^{\circ} \mathrm{N}\end{array}$ & $\begin{array}{l}76^{\circ} \mathrm{W} \\
92^{\circ} \mathrm{W}\end{array}$ & $\begin{array}{r}75 \\
184\end{array}$ & $\begin{array}{l}1.95 \times 10^{6} \\
8.23 \times 10^{6}\end{array}$ & $\begin{array}{l}1.39 \times 10^{5} \\
2.87 \times 10^{5}\end{array}$ & $\begin{array}{l}244 \\
406\end{array}$ & 20.0 & $\begin{array}{l}19.0 \\
21.0\end{array}$ & $\begin{array}{l}3.9 \\
4.5\end{array}$ & $\begin{array}{l}0.015 \\
0.018\end{array}$ \\
\hline $\begin{array}{l}\text { Memphremagog, } \\
\text { Que. }\end{array}$ & 1 & & & & 000 & & 107 & 11.0 & & 4.5 & 0.014 \\
\hline Colorado & 5 & $40^{\circ} \mathrm{N}$ & $106^{\circ} \mathrm{W}$ & $\begin{array}{l}2,300 \\
3,900\end{array}$ & $\begin{array}{r}4.5 \\
3,910\end{array}$ & $\begin{array}{r}212 \\
6,253\end{array}$ & $\begin{array}{l}10 \\
81\end{array}$ & $\begin{array}{l}2.0 \\
7.0\end{array}$ & 17.0 & $\begin{array}{r}7.0 \\
12.0\end{array}$ & $\begin{array}{l}0.008 \\
0.007\end{array}$ \\
\hline rater Lake & $\begin{array}{l}1 \\
1\end{array}$ & & & $\begin{array}{r}1,882 \\
882\end{array}$ & $\begin{array}{r}4,800 \\
51,000\end{array}$ & & $\begin{array}{l}589 \\
113\end{array}$ & $\begin{array}{l}10.8 \\
14.2\end{array}$ & $\begin{array}{l}15.9 \\
19.0\end{array}$ & $\begin{array}{l}3.9 \\
4.3\end{array}$ & $\begin{array}{l}0.010 \\
0.015\end{array}$ \\
\hline Columbia & 16 & $48^{\circ} \mathrm{N}$ & $125^{\circ} \mathrm{W}$ & 10 & 230 & 1 & 54 & 4.7 & 12.7 & 4.9 & 0.005 \\
\hline $\mathrm{Coa}$ & & $54^{\circ} \mathrm{N}$ & 132 & 116 & 5,100 & 7,1 & 283 & 14.0 & 23.1 & 7.8 & 0.023 \\
\hline $\begin{array}{l}\text { British Columbia } \\
\text { (Interior) }\end{array}$ & 4 & $\begin{array}{l}49^{\circ} \mathrm{N} \\
50^{\circ} \mathrm{N}\end{array}$ & $\begin{array}{l}119^{\circ} \mathrm{W} \\
120^{\circ} \mathrm{W}\end{array}$ & $\begin{array}{r}490 \\
1.138\end{array}$ & $\begin{array}{r}32.3 \\
319\end{array}$ & $\begin{array}{r}568 \\
1.786\end{array}$ & $\begin{array}{r}9 \\
20\end{array}$ & $\begin{array}{l}4.0 \\
7.0\end{array}$ & $\begin{array}{l}18.0 \\
20.2\end{array}$ & $\begin{array}{l}5.0 \\
6.0\end{array}$ & $\begin{array}{l}0.012 \\
0.017\end{array}$ \\
\hline Janan & 34 & $\begin{array}{l}31^{\circ} \mathrm{N} \\
44^{\circ} \mathrm{N}\end{array}$ & $\begin{array}{l}130^{\circ} \mathrm{E} \\
145^{\circ} \mathrm{E}\end{array}$ & $\begin{array}{r}10 \\
1,478\end{array}$ & $\begin{array}{r}0.4 \\
64,770\end{array}$ & $\begin{array}{r}63 \\
25,450\end{array}$ & $\begin{array}{r}6 \\
425\end{array}$ & $\begin{array}{r}1.0 \\
16.0\end{array}$ & $\begin{array}{l}15.5 \\
31.1\end{array}$ & $\begin{array}{r}3.6 \\
16.8\end{array}$ & $\begin{array}{l}0.009 \\
0.038\end{array}$ \\
\hline Poland & 15 & $54^{\circ} \mathrm{N}$ & $21^{\circ} \mathrm{E}$ & $\sim 150$ & $\begin{array}{r}6.6 \\
860\end{array}$ & $\begin{array}{r}257 \\
2,933\end{array}$ & $\begin{array}{r}7.5 \\
42.5\end{array}$ & $\begin{array}{r}4.0 \\
11.5\end{array}$ & & & \\
\hline England & 8 & $54^{\circ} \mathrm{N}$ & $3^{\circ} \mathrm{W}$ & $\begin{array}{r}40 \\
145\end{array}$ & $\begin{array}{r}10.2 \\
894\end{array}$ & $\begin{array}{r}319 \\
2,990\end{array}$ & $\begin{array}{r}14.5 \\
76\end{array}$ & $\begin{array}{r}7.6 \\
25.4\end{array}$ & $\begin{array}{l}13.7 \\
15.8\end{array}$ & $\begin{array}{r}6.7 \\
13.4\end{array}$ & $\begin{array}{l}0.006 \\
0.003\end{array}$ \\
\hline orth Am & 67 & $\begin{array}{l}41^{\circ} \mathrm{N} \\
50^{\circ} \mathrm{N}\end{array}$ & $\begin{array}{l}72^{\circ} \mathrm{W} \\
95^{\circ} \mathrm{W}\end{array}$ & $\begin{array}{r}75 \\
450\end{array}$ & $\begin{array}{c}1.7 \\
8.23 \times 10^{6}\end{array}$ & $\begin{array}{r}130 \\
2.87 \times 10^{5}\end{array}$ & $\begin{array}{l}4.2 \\
406\end{array}$ & $\begin{array}{r}1.9 \\
20.0\end{array}$ & $\begin{array}{l}18.5 \\
26.5\end{array}$ & $\begin{array}{r}3.9 \\
12.2\end{array}$ & $\begin{array}{l}0.014 \\
0.040\end{array}$ \\
\hline
\end{tabular}

where $\rho_{\mathrm{e}}$ and $\rho_{\mathrm{h}}$ are the epilimnion and hypolimnion densities respectively. This quantity is not always well-defined in the present study; estimates are provided for collections of lakes.

The total collection of 150 lakes encompasses a wide range of conditions; we should expect to uncover the influence of lake geometry on stratification most easily with a data set for which the external forcing (wind, heat fluxes) is similar for all lakes, and for which the lengths and depths vary over wide ranges. A composite set of 67 lakes in the mid-North American continent (Minnesota, Northwest Ontario, southern Ontario, Finger Lakes, Memphramagog, Great Lakes) will be particularly useful. This entire region is within or adjacent to the Great Lakes basin and therefore subject to as similar a set of conditions as it would be possible to expect for such an extreme range of physical dimensions.

In developing relations between lake geometry and thermal structure we shall restrict ourselves mainly to two data sets: data from the 20 lakes in Minnesota, and from the 67 lakes in the vicinity of the Great Lakes basin (including the Minnesota lakes). Other data sets will be examined for comparison and confirmation.

\section{A Regional Stratification Boundary}

Figure 2 locates Minnesota, Northwest Ontario, and Polish lakes on a length-depth plane; the symbols indicate whether the lakes are stratified. A similar diagram is given by Lathrop and Lillie 


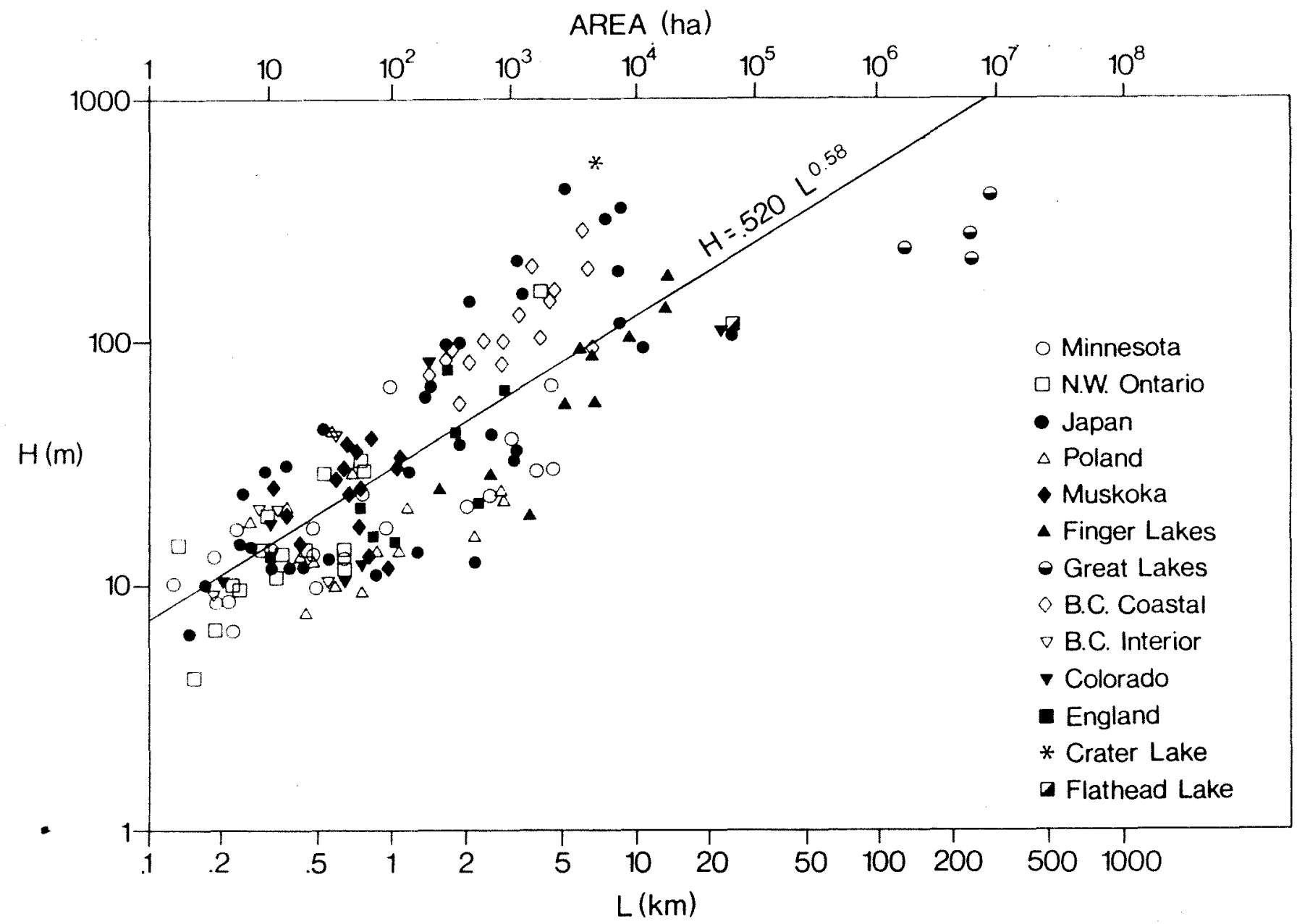

FIG. I. Geometric data, $L$ and $H$ (length or square root of surface area and maximum depth) for all stratified lakes studied.

(1980). We have reason to believe (Table 1, J. Jedrasik, Department of Hydrology and Climatology, Gdansk University, Gdansk, Poland; personal communication) that the lakes in Poland have similar properties to those of the North American lakes. This is a most interesting display, for it indicates a boundary between stratified and unstratified lakes that can be described as a function of length, $L$, and maximum depth, $H$. We have marked on Figure 2 a dashed line that seems to delineate this boundary. For a given surface area a lake must have a minimum depth in order to stratify; as surface area increases, the minimum required depth also increases.

\section{Ratio of Thermocline Depth (h) to Maximum Depth (H)}

The ratio $\mathrm{h} / \mathrm{H}$ (designated hereafter as $\alpha$ ) was computed for each of the 150 stratified lakes and the relative frequency of occurrence of different values of $\alpha$ is shown in Figure 3. Ninety percent of the lakes have thermocline depths less than half the maximum depth $(\alpha \leq)$; there are no lakes exhibiting seasonal stratification with the thermocline depth greater than $70 \%$ of the maximum depth ( $\alpha$ $=0.7)$. This apparent cut-off in allowable values of $\alpha$ also demands explanation. 


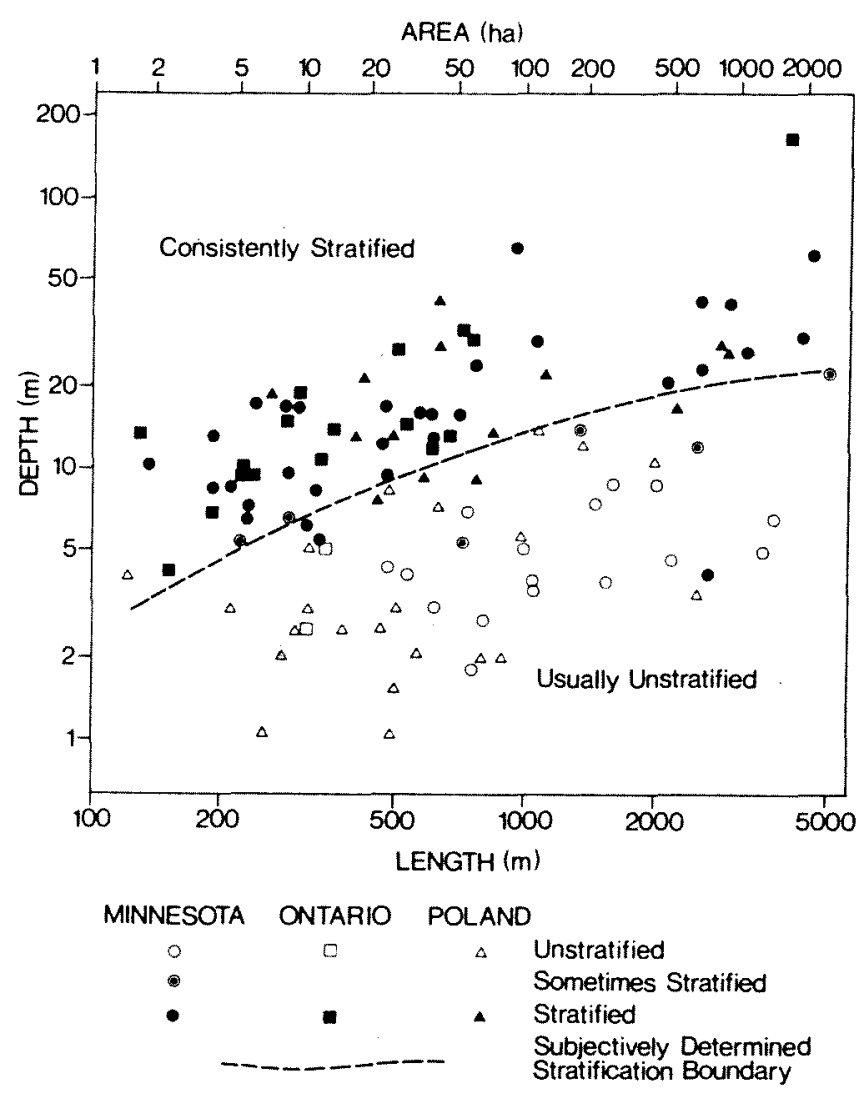

FIG. 2. Geometric data, $H$ and $L$, for a collection of both stratified (closed symbols) and unstratified (open symbols) lakes. This plot suggests a stratification boundary that can be represented by a curve on the $H, L$ plane.

\section{Simple Linear Relation Between Thermocline Depth and Lake Length and Depth}

Despite its obvious shortcomings, a straightforward linear equation is often a good way to express an empirical relation. We propose a trial function of the form

$$
\mathrm{h}=\mathrm{A}+\mathrm{BL}+\mathrm{CH}
$$

The parameters $\mathrm{A}, \mathrm{B}$, and $\mathrm{C}$ are easily determined by a least-square-error technique. Partial correlation coefficients between the dependent variable and each of the two independent variables, the overall correlation coefficient for the predictor, and the root mean square error are also computed (Panofsky and Brier 1968).

The analysis was first performed for the collection of Minnesota lakes. The partial correlation coefficients (Table 2) show a strong dependence of thermocline depth upon length, and a much

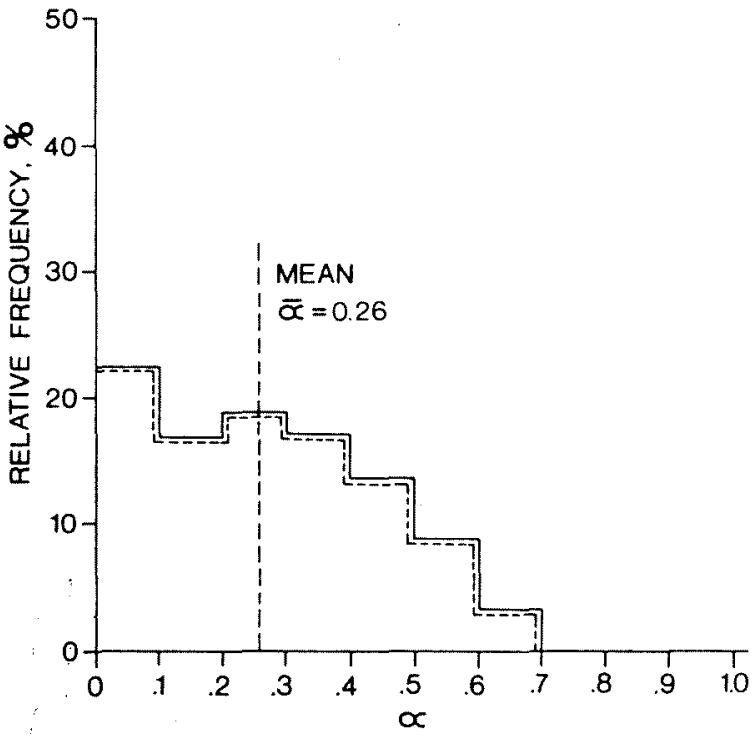

FIG. 3. Frequency distribution of values of the rates of thermocline depth to maximum depth $(a=h / H)$ for 150 stratified lakes.

weaker, possibly insignificant, dependence of thermocline depth upon maximum depth. The overall correlation coefficient is 0.95 .

Broadening the data base to include the midNorth American lakes produces a different result. The partial correlation coefficients now suggest the most significant independent variable is depth, not length. Indeed, the partial correlation coefficient for length is negative. The overall correlation coefficient remains high at $\mathbf{0 . 8 2}$. The Minnesota collection contains no lake of length greater than 5,000 $\mathrm{m}$, whereas the $67 \mathrm{mid}-$ North American collection includes the Laurentian Great Lakes. Data from Japan, also encompassing a large range of lake lengths, yield similar results. We conclude that large and small lakes behave differently.

Assuming that the empirical relation is valid over a range of $\alpha$ from 0 to a cut-off value of $\alpha_{\max }$, we could rework equation 1 into an equation yielding the minimum value of $\mathrm{H}$ required for a lake of length $L$ before stratification is assured:

$$
H \geq \frac{(A+B L)}{\left(\alpha_{\max }-C\right)}
$$

Using the values of $\mathrm{A}, \mathrm{B}$, and $\mathrm{C}$ developed for the Minnesota lakes, the value of $\alpha_{\max }$ may be determined by a least-square-error fit to the stratification boundary sketched on Figure 2 . The value of $\alpha_{\max }$ is found to be 0.55 . This result suggests that 
TABLE 2. Least-square-error fit of the curve $h=A+B L+C H$ to the two data sets chosen for detailed analysis. $r_{31.2}$ is the partial correlation coefficient of $h$ on $L$ and $r_{32.1}$ is the partial coefficient of $h$ on $H$. rand $\sigma$ are the total correlation coefficient and the rms error of the above curve. Table $2 A$ is compiled using those lakes of lengths less than or equal to 5,000 $\mathrm{m}$ (areas less than or equal to 2,500 ha). Table $2 B$ is compiled using all lakes in the mid-North American collection.

\begin{tabular}{lccccccr}
\hline & $\mathrm{A}(\mathrm{m})$ & $\mathrm{B}$ & $\mathrm{C}$ & $\mathrm{r}_{31.2}$ & $\mathrm{r}_{32.1}$ & $\mathrm{r}$ & $\sigma(\mathrm{m})$ \\
\hline & & & A. Lakes with L $<5,000 \mathrm{~m}$ \\
Minnesota & 3.7 & $2.4 \times 10^{-3}$ & $2.5 \times 10^{-3}$ & 0.92 & 0.03 & 0.95 & 1.2 \\
Mid-North America & 4.3 & $2.0 \times 10^{-3}$ & $3.0 \times 10^{-3}$ & 0.79 & 0.04 & 0.85 & 1.5 \\
& \multicolumn{7}{c}{ B. All Lakes } \\
Mid-North America & 5.29 & $-1.1 \times 10^{-5}$ & $5.8 \times 10^{-2}$ & -0.011 & 0.61 & 0.82 & 2.6 \\
\hline
\end{tabular}

the empirical formula is consistent with the observed stratification boundary and also highlights the importance of the ratio, $\alpha$.

We tested other empirical forms for lakes of lengths less than $5,000 \mathrm{~m}$, including a dependence on the square root of length as proposed by other researchers. We could not improve significantly on the linear relation, possibly because we have neglected the elongation of the lakes and their orientation to the prevailing winds.

\section{Wind Stress and Buoyancy}

Although length and depth influence the thermal structure of lakes, the primary variables are wind stress and buoyancy. The latter is defined as the product of the density difference between the epilimnion and the hypolimnion with the gravitational acceleration, $g \Delta \rho=g(\rho h-\rho e)$ or $\rho h g^{\prime}$ in terms of the reduced gravity $g^{\prime}$, defined earlier, and is the cumulative result of surface heat flux. Wind stress and buoyancy oppose one another; the larger the wind stress, the more mechanical energy there is available to mix the lake; the larger the buoyancy, the more mechanical energy is required to modify or to destroy the stratification. At seasonal or climatological time scales, wind stress and surface heat flux will be roughly similar over the regions spanned by the various collections of lakes; this homogeneity allows the dependence of thermocline depth on geometric factors to appear without explicit concern for the basic forcing variables.

It is convenient to represent the wind stress, $t$, as the product of the water density, $p$, and the square of a velocity scale, $u_{*}$, called the friction velocity.

$$
\tau=\rho u_{*}^{2}
$$

The friction velocity is typical of the turbulent velocity fluctuations caused by the wind at the water surface. Velocity scales of mean motion also depend on the wind stress or friction velocity. The buoyancy and the wind stress can be combined into a single variable having the dimension length, $h_{*}$ :

$$
\mathrm{h}_{*}=\frac{\rho \mathrm{u}_{*}^{2}}{\mathrm{~g} \Delta \rho}=\frac{\mathrm{u}_{*}^{2}}{\mathrm{~g}^{\prime}}
$$

$\mathrm{h}^{*}$ can be shown to be related to the vertical scale of turbulent fluctuations at the interface between the warm and the cool water. A water particle at the interface between the warm and cool layers and impelled downward with a velocity $u^{*}$, would travel a distance $h^{*} / 2$ before being brought to a halt by the buoyancy force, in the absence of other forces, including friction.

Dimensional analysis suggests the form:

$$
\left(\frac{h}{\mathrm{H}}\right)=\alpha=\mathrm{F}\left(\frac{\mathrm{L}}{\mathrm{H}}, \frac{\mathrm{h}_{*}}{\mathrm{H}}\right)
$$

where the function $F$ is yet to be determined. Of course, the formation and decay of the thermocline is a dynamic process depending on heat and momentum fluxes and the above relations do not include time. Such a relation can serve only as an "envelope" of possible configurations but may have some validity by virtue of the fact that major alterations in thermal structure of lakes are accomplished relatively quickly by episodic wind events. Thus we might, as a first attempt, apply this relation to the specific time of maximum heat content prior to the onset of significant convection induced by surface cooling. 


\section{Direct Wind Stirring and Shear-generated Turbulence}

Dealing with small and medium sized lakes in which the effects of the earth's rotation are neglected, Spigel and Imberger (1980) presented scaling arguments to delineate the relative importance of two processes by which the upper mixed layer, or epilimnion, is thickened. The first process is the stirring action of the turbulence created at the water surface by the wind. The second process is the turbulence generated at the base of the mixed layer when the velocity shear associated with internal seiches becomes large in relation to the stabilizing effects of the density contrast between the warm and cold layers. Velocity shears generated by the mean circulation that develops following prolonged wind events are shown to have little effect.

SI define a range of lake mixing regimes in response to suddenly imposed wind stresses. These range from a situation in which the contribution of velocity shear to mixing is negligible and thermocline deepening, if it occurs at all, is accomplished via surface stirring (Kraus and Turner 1967), to a catastrophic situation in which the two-layer system is obliterated by shear-generated turbulence within the first half-period of the internal seiche. The latter situation can occur, particularly in long narrow lakes, when the stratification is weak (early summer or late fall). Our observations of the heating phase of lakes in the temperate zone (Fig. 4) are that from the time that stratification is firmly established until the time of maximum heat content-thermocline deepening is progressive, each significant wind event reestablishing an upper mixed layer and lowering the thermocline by a finite amount.

This raises the possibility that the thermocline lies at a depth where a major wind event will deepen it somewhat through shear-induced mixing at the interface and stirring through the mixed layer, but not catastrophically as in the more violent regimes described by SI. Deepening of the thermocline also tends to reduce shear (up to a point, as we shall see later). The thermocline depth should then be the result of the wind stress and density contrast (combined as the length scale $h_{*}$ ) obtained at the most recent significant wind event, in addition to the geometric controls.

A paper by Pollard et al. (1973) proposed that the mixed layer depth in the open ocean be determined by an internal Froude number criterion
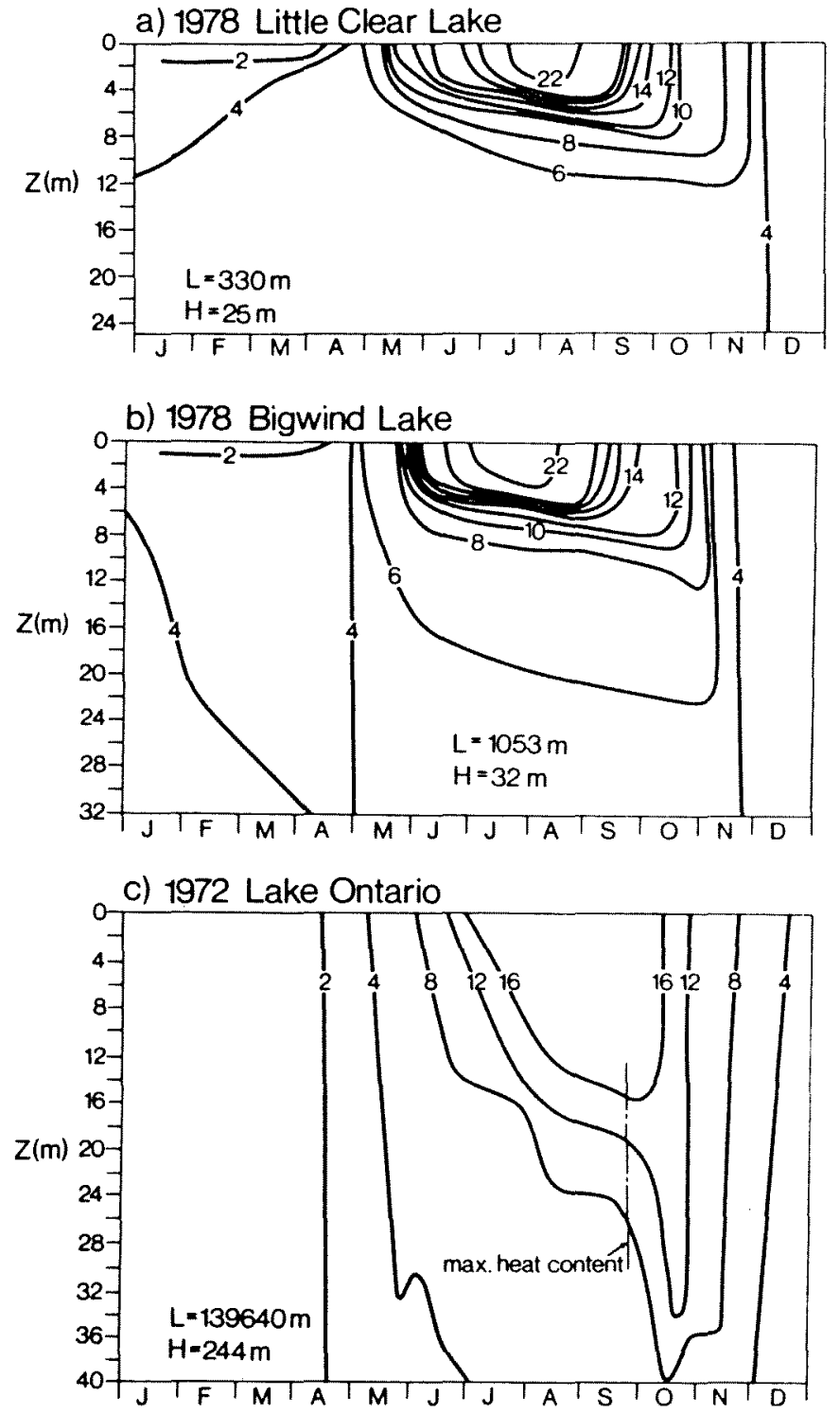

FIG. 4. Seasonal temperature structures depicted as time histories of isotherm depths for two Muskoka lakes and Lake Ontario. The figures for the Muskoka lakes are used with the permission of Reid et al. 1983. The sampling interval is approximately bi-weekly.

wherein the mixed layer depth adjusts to the condition

$$
\frac{U_{\max }}{\left(g^{\prime} h\right)^{1 / 2}}=F_{i} \text { crit }
$$

where $U_{\max }$ is the maximum shear velocity generated across the base of the mixed layer, and $\mathrm{g}^{\prime}$ is the reduced gravity defined earlier. The mixing regimes defined by SI employ a similar Froude 
number scaling. When $F_{1}=U /\left(g^{\prime} h\right)^{1 / 2}$ is small enough (substantially less than one), shear-induced mixing will be relatively unimportant. More recently, Deardorff (1983) attempted a synthesis of laboratory data into an empirical formula that avoids the "all or nothing" singularity of critical internal Froude numbers and portrays the rate of thermocline deepening as a continuous function of stirring, convection, and shear-induced turbulence. The relative importance of shear-induced mixing continues to depend on the internal Froude number defined above. For small lakes, SI show that the maximum velocity shear, $U_{\max }$, across the interface occurs a time after the onset of the wind stress equal to one quarter of the period of the fundamental internal seiche and has a value

$$
\mathrm{U}_{\mathrm{max}}=\mathrm{u}_{*}^{2} \mathrm{~L}\left(2 \mathrm{~h}\left[\mathrm{~g}^{\prime} \frac{\mathrm{h}(\mathrm{H}-\mathrm{h})}{\mathrm{h}}\right]^{1 / 2}\right)^{-1}
$$

in a lake of length (L) aligned with the wind and with a constant depth $(\mathrm{H})$.

We postulate therefore that the thermocline depth at seasonal time scales adjusts to the condition

$$
\text { - } \quad \mathrm{R}_{\mathrm{i}}=\left(\mathrm{F}_{\mathrm{i}}\right)^{-1}=\frac{\left(\mathrm{g}^{\prime} \mathrm{h}\right)^{1 / 2}}{\mathrm{U}_{\max }}=\beta
$$

where $U_{\max }$ for small lakes of constant depth is given by equation 6 above, and $\beta$, now defined as the inverse of a critical internal Froude number (a bulk Richardson number, $R_{i}$ ), is a constant of order 1 , yet to be determined. With some manipulation, expressions (6) and (7) may be presented in terms of the ratio $h / H=\alpha$.

$$
\alpha^{2}(1-\alpha)^{1 / 2}=\frac{\beta}{2}\left(\frac{h_{*}}{\mathrm{H}} \cdot \frac{\mathrm{L}}{\mathrm{H}}\right)
$$

For small $\alpha$, an approximate solution to equation $(8)$ is

$$
\mathrm{h}=\left(\frac{\beta}{2} \mathrm{~h}_{*}\right)^{1 / 2} \mathrm{~L}^{1 / 2}
$$

Note the apparent dependence of $h$ on the square root of length (L).

\section{Extension to Very Large Lakes}

In large lakes, the theoretical period of the fundamental internal seiche ( $\mathrm{Ti}$ ) may become comparable to or longer than the local inertial period (TI = $12 \mathrm{hrs} / \sin \Phi)$, where $\Phi$ is the latitude of the loca- tion. When this occurs, the effects of the earth's rotation can no longer be ignored, and indeed they may come to dominate the seiching motion (Mortimer 1974). Equation 8 can apply only when Ti/TI is substantially less than one.

$$
\mathrm{T}_{\mathrm{i}} / \mathrm{T}_{1}=\mathrm{Lf} \pi^{-1}\left(\mathrm{~g}^{\prime} \mathrm{h}(\mathrm{H}-\mathrm{h}) / \mathrm{H}\right)^{-1 / 2}
$$

where $f=2 \omega \sin \Phi$ is the local Coriolis parameter and $\omega$ is the angular speed of rotation of the earth. Dropping the constant, we obtain the ratio

$$
S=L\left[\left(g^{\prime} h(H-h) / H\right)^{1 / 2} f^{-1}\right]^{-1}=L / L_{R}
$$

where $L_{R}$ is known as the internal Rossby radius of deformation, a length scale at which the earth's rotation significantly modifies the internal seiche (Simons 1980, Csanady 1982). A typical value of $\mathrm{L}_{\mathrm{R}}$ for mid-North American lakes is $3,000 \mathrm{~m}$. From simple Ekman theory valid for very large water bodies (Simons 1980) it can be shown that a maximum velocity shear following the application of a wind stress to a very large body of water is produced after a time $\mathrm{TI} / 2$ and has the value

$$
\mathrm{U}_{\max }=\mathrm{u}_{*}^{2} /(\mathrm{fh})
$$

Substituting this into equation 7 and solving for $h$, we get a relation equivalent to that of equation 9 .

$$
h=\gamma\left(u_{*}^{4} g^{1-1} f^{-2}\right)^{1 / 3}=\gamma\left(h \mu * f^{-2}\right)^{1 / 3}
$$

where $\gamma$ is related to the critical bulk Richardson number, $\beta$;

$$
\gamma=1.6 \beta^{23}
$$

For Lake Ontario, $\mathrm{S}$ is of order 30 (rotational effects dominate totally); typical values of $u_{*}$ and $\mathrm{g}^{\prime}$ are $0.01 \mathrm{~m} / \mathrm{s}$ and 0.018 respectively, $f$ has a value of $10^{-4}$ radians $/ \mathrm{s}$. The thermocline depth at maximum heat content averages $20 \mathrm{~m}$ (Boyce et al. 1977), a value also typical of Lakes Erie (central and eastern basins), Huron, and Michigan despite substantial variations in maximum depth and area among them. From these data, $\gamma$ is approximately 5 , and $\beta$ is about 6 .

\section{Test of Equation 8 Against Data From Small Lakes}

Recognizing that equation 8 applies only to "small" lakes, we ordered our data sets by increasing values of the parameter $S$, using values of $g^{\prime}$ given in Table 1. Taking subsets of the data, each time 


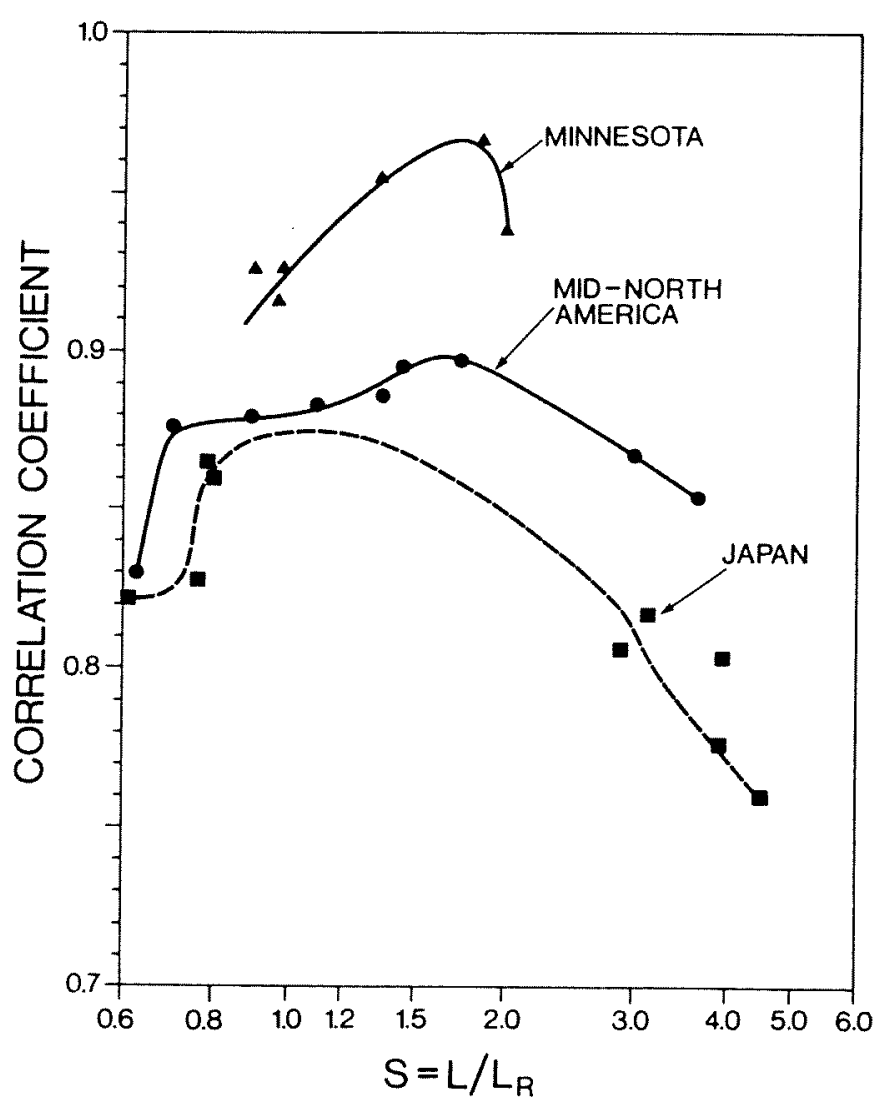

FIG. 5. Plot of correlation coefficient for predictor $8 b$ $(m=1)$ against $S$, the ratio of lake length $(L)$ to the internal rossby radius of deformation $\left(L_{R}\right)$ (see equation 11). Peak correlations occur near $S=1$. this is taken as confirming evidence for the influence of the earth's rotation upon the internal seiche in large lakes.

including higher values of $\mathrm{S}$, the value of the constants in the right hand side of equation $8, \beta \mathrm{h}_{*} / 2$ defined henceforth as $D$, was sought; that minimized the error of equation 8 as a predictor of thermocline depth. Once an optimum D was determined for each trial, the linear correlation coefficient and the rms error of the predictor against the observations were established. If rotational effects are present, the correlation coefficient should begin to decrease, once a critical value of $S$ has been exceeded (Fig. 5). Although the process is noisy, an increase of $S$ beyond the value of 1 or 2 produces a decrease in the correlation coefficient for the data sets tested. This is consistent with experience in coastal oceanography (Csanady 1982) and is confirming evidence that the big lake-small lake differences are a consequence of the earth's rotation. We then eliminated lakes with values of S greater than 1.4 from attempts to further refine equation 8 as a predictor of thermocline depth. The same test applied to the linear trial function (equation 1) yielded a similar critical value of $\mathrm{S}$.

The idealization of constant depth does not fit real lakes. The period of the internal seiche is affected by variable bottom topography, but it is not a simple matter to compute the result. We propose a rough accounting for the effects of sloping sides by allowing the effective length of the basin, important in determining the seiche period and hence the maximum shear velocity, to vary with the maximum thickness of the hypolimnion. We replace $\mathrm{L}$ in the constant depth model by $\mathrm{L}[\mathrm{CH}-$ h) $/ \mathrm{H}]^{\mathrm{m}}$ in the variable depth model. When $\mathrm{m}=0$, we recover the original equation 8 for constant depth. When $m=1$, the cross-section of the basin is approximately conical. Equation 8 modified for variable depth becomes

$$
\alpha^{2}(1-\alpha)^{1 / 2-m}=M=\frac{\mathrm{DL}}{\mathrm{H}^{2}}
$$

where $m$ and $D$ are now to be estimated by the least-square-error method. But in order to compare equations 1 and 15 on an equal footing, we must allow the same number of empirically determined parameters to each. Recall that equation 1 contains two slopes and an intercept, the latter being of the order of a few meters. We therefore propose a version of equation 15 that retains an additive constant or intercept.

$$
h_{p}=H \alpha(D, m, L, H)+E
$$

where $\alpha$ is the solution of equation 15 in terms of $\mathrm{D}, \mathrm{m}, \mathrm{L}$, and $\mathrm{H}$ with the parameters $\mathrm{D}, \mathrm{m}$, and $\mathrm{E}$ being determined by a numerical least-square-error method. The linear regression of $h$ on the predictor $h_{p}$ was calculated; the slope and intercept were found to be close to 1.0 and 0.0 respectively. The final results computed with optimum data sets ( $\mathrm{S}$ $\leq 1.4)$ are displayed in Table 3 . These are not particularly sensitive to the value of the shape exponent (m) but it can be demonstrated that the best correlations are obtained with $m$ greater than zero

In its final form, equation 16 is as successful a predictor of thermocline depth as the other purely empirical relations, according to correlation coefficients and rms errors given in Table 3. 
TABLE 3. Least-square-error fit of the SI relationship (equation 16 with intercept) to the various data collections. The column labelled $\alpha$ gives the average ratio of thermocline depth to maximum depth. $S_{\max }$ (defined by eq. 15) defines the subset of lakes included in the analysis; $S<S_{\max }$. Those subsets that exclude the lakes subject to appreciable rotational effects yield the best correlations. $E$, $D$, and $m$ are three parameters defining the SI relation; they are determined by a numerical leastsquare-error algorithm and they are explained in the text. $r$ and $\sigma$ are the correlation coefficient and the rms error between the observed and the predicted thermocline depths using the developed SI relationship. The correlation coefficients for the simple linear regression formula using the same data are shown for comparison.

\begin{tabular}{|c|c|c|c|c|c|c|c|c|c|}
\hline & Collection & $\bar{\alpha}$ & $\underset{\max }{\mathrm{S}}$ & $\begin{array}{c}\mathrm{E} \\
(\mathrm{m})\end{array}$ & $\underset{(\mathrm{m})}{\mathrm{D}}$ & $\mathrm{m}$ & $\mathrm{r}$ & $\begin{array}{c}\sigma \\
(\mathrm{m})\end{array}$ & $\begin{array}{c}r \\
\text { (Linear) }\end{array}$ \\
\hline Minnesota & (20) & 0.36 & 1.3 & 1.4 & 0.072 & 1.4 & 0.96 & 0.8 & 0.96 \\
\hline Japan & (27) & 0.22 & 0.4 & 1.2 & 0.066 & 0.7 & 0.87 & 1.7 & 0.88 \\
\hline Mid-North-America & (57) & 0.30 & 1.3 & 1.9 & 0.071 & 1.8 & 0.92 & 1.1 & 0.88 \\
\hline Poland & (15) & 0.31 & 1.1 & -0.15 & 0.070 & 0.8 & 0.96 & 0.6 & 0.97 \\
\hline England & (6) & 0.48 & 1.0 & -4.5 & 0.53 & 0.4 & 0.94 & 2.4 & 0.93 \\
\hline Muskoka & (16) & 0.31 & 0.5 & 0 & 0.141 & 0.5 & 0.47 & 1.1 & 0.52 \\
\hline B.C. Coastal & $(8)$ & 0.09 & 1.0 & 0 & 0.076 & 0.5 & 0.78 & 1.0 & 0.90 \\
\hline Colorado & (5) & 0.33 & 0.4 & 0 & 0.078 & 0.5 & 0.73 & 1.2 & 0.77 \\
\hline NW Ontario & (17) & 0.32 & 1.2 & 0 & 0.088 & 0.5 & 0.88 & 1.2 & 0.78 \\
\hline Finger & $(5)$ & 0.21 & 1.1 & 0 & 0.065 & 0.5 & 0.93 & 1.4 & 0.99 \\
\hline
\end{tabular}

\section{Stratification Boundary}

We now resume the discussion of the boundary between lakes that stratify regularly in summer and those that do not, a boundary that we recognize to depend on both $\mathrm{L}$ and $\mathrm{H}$. Note that the left hand side of equation $15, \alpha^{2}(1-\alpha)^{1 / 2-m}$, has a maximum value between $\alpha=0$ and $\alpha=1$ provided that $m$ is less than or equal to $1 / 2$. When $m=0$ (lake of constant depth), $\mathrm{M}$ has a maximum value of 0.286 when $\alpha=0.80$; the equation has no solution when $M$ is greater than 0.286 . In terms of the theory developed by SI, we interpret this to mean that as long as $\alpha$ is less than 0.80 and $M$ is less than 0.286 , the lake can adjust to an increase in wind stress by deepening the thermocline without entering the mixing regime where shear-induced mixing dominates and ultimately destroys the stratification. When $m$ is greater than $1 / 2$, equation 15 can be balanced with any value of $M$ because, according to our very crude model, as the thermocline moves deeper, the effective length of the lake governing the internal seiche becomes smaller and the velocity shear becomes relatively less important. Needless to say, physical interpretation of this feature is speculative at best, and we are convinced that the reason for the existence of a cut-off value for $\alpha$ has to do with a process neglected by the original SI scaling theory.

Using the observation that $\alpha$ is limited to values less than or equal to a cut-off value, $\alpha_{\max }$, near 0.6 , we may state the stratification boundary

$$
\mathrm{M}<\alpha_{\max }^{2}\left(1-\alpha_{\mathrm{nax}}\right)^{1 / 2-\mathrm{m}}
$$

or

$$
\mathrm{H}>\left[\frac{\beta \mathrm{h}_{*}}{2 \alpha_{\max }^{2}\left(1-\alpha_{\max }\right)^{1 / 2-m}}\right]^{12} \mathrm{~L}^{1 / 2}
$$

where the inequality must be satisfied in order for the lake to stratify. The stratification boundary of Figure 2 is adequately represented by the curve $\mathrm{H}$ $=0.34 \mathrm{~L}^{1 / 2}$ ( $\mathrm{H}$ and $\mathrm{L}$ in meters $)$. The curve given by Lathrop and Lillie (1980), while of a different functional form, lies close to $H=0.23 \mathrm{~L}^{1 / 2}$ over the range of $L$ of interest to us.

From Table 3, a value of $\mathrm{D}$ typical for the data of Figure 2 is $0.07 \mathrm{~m}$, and using $\mathrm{m}=1$, the boundary curve requires $\alpha_{\max }$ to be 0.62 . The Lathrop and Lillie curve yields $\alpha_{\max }=0.66$.

\section{DISCUSSION AND CONCLUSIONS}

Viewed as a trial function in the same spirit as equation 1 , equation 16 , the extension of equation 8 to include an intercept, performs as well as any empirical model we have tested. Given the uncertainties in $\mathrm{h}, \mathrm{g}^{\prime}, \mathrm{u}^{*}$, etc. it is perhaps unrealistic to expect a significant improvement over other empir- 
ical forms based on the same number of free parameters. Its form is consistent with the findings of earlier workers, notably the dependence of thermocline depth upon the square-root of length proposed by Patalas (1984) and Ragotzkie (1978).

The main advantage of equation 8 (or 16) is its physical basis that includes both wind stress and buoyancy. According to the physical reasoning governing its choice, during the heating season, at seasonal time scales, the thermocline lies at a depth where shear-generated turbulence (created by the internal seiche in small lakes, or by inertial motion in very large lakes) from major storm events caused limited, but not catastrophic, mixing. The bulk Richardson Number associated with the shearing motion has a lower bound greater than 1 . Such a notion is an inappropriate model for the day-to-day evolution of the thermal structure, but it serves as an envelope for the gross features of thermal structure.

Since surface wind waves are strongly fetchdependent for most small lakes, might their contribution to turbulence explain the fetch-dependence of thermocline depth? We are indebted to M. A. Donelan (personal communication, National Water Research Institute, Burlington, Ontario) for a discussion of this possibility. The contribution of the surface wave field to turbulence involves two principal mechanisms, that of forward breaking which is confined vertically to a few wave heights, and the more subtle effects of the wave orbital velocities. Orbital velocities are irrotational to a first approximation, but they extend to greater depths than the influence of wave-breaking. Kitaigorodski and Lumley (1983) and Kitaigorodski et al. (1983) concluded the turbulent spectrum below the water surface is influenced by the wave field. Jones (1985) concluded on the other hand that the boundary layer nature of windgenerated turbulence is unaffected by orbital motions a distance equivalent to a few wave heights below the surface. More work is needed to resolve this question. Donelan (personal communication) suggests that the surface wave effects will be small at the thermocline depth. Fetches in the Great Lakes are an order of magnitude greater than those of the small lakes for which the SI scaling seems appropriate. They are large enough that the wave field is not always fetch-limited. The shallowness of Great Lake thermoclines in relation to the size of the lakes is consistent with surface wave fetch-dependence, but the SI scaling, modified to account for the effects of the earth's rotation, also explains this shallowness. We find the SI scaling to be the more plausible argument.

In fitting equation 8 to available data, the parameter D, a length scale containing the "critical" internal Froude number, the wind stress, and the buoyancy term, is determined empirically on the assumption that it is constant for each collection of lakes. Individual values of wind stress and buoyancy are unknown but are presumed not to vary greatly from representative regional values. With two exceptions, lakes in England, and the Muskoka Lake collection from southern Ontario, $\mathrm{D}$ ranges from 0.065 to $0.088 \mathrm{~m}$. English lakes for which $\mathrm{D}$ is determined to be almost an order of magnitude larger $(0.53 \mathrm{~m})$ are nevertheless wellfitted by equation 8 . Compared with other lakes, temperature differences between epilimnion and hypolimnion in these lakes are small, indicative of strong winds in the spring that delay the formation of seasonal stratification. The difference between English lakes and the others may be related to climatic factors. The range of $\mathrm{L}$ and $\mathrm{H}$ reported in the Muskoka collection is small; the data are too clustered to yield a reliable estimate of $D$. For the other collections, the narrow spread of empirically determined values of $\mathrm{D}$ may be the consequence of having drawn data exclusively from the temperate zone. Note that the empirical relation proposed by Ragotzkie (1978) yields a D value of 0.12 , somewhat larger, but close to the values we report. From rough estimates of wind stress and temperature differences for the small North American lakes, the "critical" value of the bulk Richardson number is of order 10 . This agrees well with the value of $\beta$ found for the Great Lakes $(\beta=6)$.

Finally, we must ask why lakes generally do not exhibit stable summer stratification such that the thermocline depth is greater than 0.6 times the maximum depth. The central basin of Lake Erie, itself an exception to the rule, may provide some clues. The basin is typically $20 \mathrm{~m}$ deep, and by midAugust has a thermocline depth of $15 \mathrm{~m}(\alpha=$ 0.75 ). Stratification persists into September; the hypolimnion may become as thin as $1 \mathrm{~m}$ (Blanton and Winklhofer 1972). These same authors also noted that the hypolimnion did not always become progressively thinner but could at times increase in thickness, possibly because of entrainment of thermocline water into a turbulent hypolimnion. Ivey and Boyce (1982) confirmed this hypothesis with more detailed field data, and the phenomenon of entrainment into the hypolimnion has been simulated using models very similar to SI models men- 
tioned earlier (Ivey and Patterson 1984). Currents set up in the hypolimnion that balance the winddriven epilimnion mean flow, either by the internal seiche (small lakes) or by inertial motion (large lakes), are opposed by bottom friction; that friction force is transmitted to the body of the hypolimnion by turbulent fluctuations, a situation in some ways analogous to the effects of wind stress on the water surface. Thus when hypolimnion velocities become large enough, we must consider three sources of mixing: turbulence created in the epilimnion by wind stress; turbulence created at the interface by velocity shear; and turbulence created in the hypolimnion by bottom friction. The last source becomes more important as the hypolimnion becomes thin ( $\alpha$ large). It is our view that turbulence arising from bottom friction becomes sufficiently important when the hypolimnion becomes thin $(\alpha>0.6)$ that stratification may not persist thereafter; this explains the lack of larger values of $\alpha$ in the data for stratified lakes. This also explains why the stratification "boundary" cannot be adequately explained by the SI theory as it now stands. A study of lakes that exhibit stratification for only part of the summer would clarify these ideas, possibly leading to further improvement of time-dependent models.

To conclude, we propose the following relations to predict the gross features of seasonal stratification in small lakes: The lake will exhibit seasonal stratification if

$$
\mathrm{H}>3.4\left(\frac{\tau}{\mathrm{g} \Delta \rho}\right)^{1 / 2}(\mathrm{~L})^{1 / 2}
$$

The depth of the thermocline is given by

$$
\alpha^{2}(1-\alpha)^{1 / 2-m}=4.0\left(\frac{\tau}{\mathrm{g} \Delta \rho}\right) \frac{\mathrm{L}}{\mathrm{H}^{2}}
$$

When the ratio, $\alpha$, is small $(<0.4)$, this is approximately

$$
\mathrm{h} \cong 2.0\left(\frac{\tau}{\mathrm{g} \Delta \rho}\right)^{1 / 2} \mathrm{~L}^{1 / 2}
$$

The wind stress, $\tau$, and the density contrast, $\Delta \rho$, are those obtaining at the period of interest (usually the time of maximum heat content); the wind stress is that of a typical storm; the density contrast, which depends on h to some extent, is taken as a typical value for nearby lakes, both for the chosen period. The length scales, $h, H, L$ and $h^{*}=$ $\tau / g \Delta \rho$ must all be expressed in the same units.

\section{ACKNOWLEDGMENTS}

Gorham's teaching of summer classes at Itasca State Park on the regional limnology of northwestern Minnesota provided an opport unity for further research on such matters. We thank the Itasca students for their enthusiastic assistance. David F. Parmalee, Robert P. Boyle, and David M. Bosanko (Itasca Field Biology Station, University of Minnesota) also were helpful. Clifford H. Mortimer reviewed an early draft of the manuscript. We are indebted to J. Patterson, R. Spigel, J. Imberger, and G. T. Csanady for useful comments. Tadashi Arai supplied a complete English translation of his 1964 paper and data for Japanese lakes. David W. Schindler provided data for lakes in the Experimental Lakes Area of northwestern Ontario. Kazimierz Patalas supplied additional data for northeastern Polish lakes and commented on an early draft of the manuscript. T. I. Furnass supplied data for the Lake District of northwestern England. R. Oglesby compiled data from various sources on the Finger Lakes in northern New York State. Reid, Locke, and Girard (1983) contributed data on small and medium-sized lakes in the Muskoka region of southern Ontario. K. Shortreed provided data from coastal lakes in British Columbia. T. Murphy, J. Kalff, and J. A. Stanford furnished data on interior British Columbia lakes, Lake Memphramagog (Quebec/ Vermont border), and Flathead Lake, Montana, respectively. The National Water Research Institute archives were searched for data on the Great Lakes. Information on eight Colorado mountain lakes was found in a report by Pennak (1955).

\section{REFERENCES}

Arai, T. 1964. Some relations between the thermal property of lake and its scale or fetch size (In Japanese, English summary). Geogr. Rev. Japan 37:131-137. 1981. Climatic and geomorphological influences on lake temperature. Int. Ver. Theor. Angew. Limnol. Verh. 21:130-134.

Blanton, J. O., and Winklhofer, A. R. 1972. Physical processes affecting the hypolimnion of the Central Basin of Lake Erie. Project Hypo. N. Burns and C. Ross, eds. Canada Centre for Inland Waters Paper No. 6. U.S. EPA Tech. Rep. TS-05-71-208-24.

Boyce, F. M., Moody, W. J., and Killins, B. N. 1977. Heat content of Lake Ontario and estimates of the average surface heat fluxes during IFYGL, 1972. Tech. Bull. No. 101, Can. Dep. Fish Environ.

Csanady, G. T. 1982. Circulation in the Coastal Ocean. Dordrecht, Holland: D. Reidel Publishing Co. 
Deardorff, J. W. 1983. A multi-limit mixed-layer entrainment formulation. J. Phys. Oceanogr. 13:988-1002.

Gorham, E. 1958. The physical limnology of northern Britain: an epitome of the bathymetric survey of the Scottish freshwater lochs, 1897-1909. Limnol. Oceanogr. 3:40-50.

1964. Morphometric control of annual heat budgets in temperate lakes. Limnol. Oceanogr. 9:525-529.

Horiuchi, S. 1959. A limnological study of thermal stratification of the lakes in Japan (In Japanese, English summary). Geogr. Rev. Japan 32:374-384.

Hutchinson, G. E. 1957. A Treatise on Limnology, Volume 1. New York: John Wiley and Sons.

Ivey, G. N., and Boyce, F. M. 1982. Entrainment by bottom currents in Lake Erie. Limnol. Oceanogr. 27:1029-1038., , and Patterson, J. C. 1984. A model of the vertical mixing in Lake Erie in summer. Limnol. Oceanogr. 29:553-563.

Jones, I. S. F., 1985. Turbulence below wind waves. In The Ocean Surface, eds. Y. Toba and H. Mitsuyasu, pp. 437-442. Dordrecht, Holland: D. Reidel Publishing Co.

Kitaigorodsky, S. A., and Lumley, J. L. 1983. Waveturbulence interactions in the upper ocean. Part I: The energy balance of the interacting fields of sur-

- face wind waves and wind-induced three-dimensional turbulence. J. Phys. Oceanogr. 13:1977-1987. Donelan, M. A., Lumley, J. L., and Terray, E. A. 1983. Wave-turbulence interaction in the upper ocean. Part II: Statistical characteristics of wave and turbulent components of the random velocity field in the marine surface layer. J. Phys. Oceanogr. 13:1988-1999.

Kraus, E. B., and Turner, J. S. 1967. A onedimensional model of the seasonal thermocline, Part II. Tellus 19:98-105.
Lathrop, R. C., and Lillie, R. A. 1980. Thermal stratification of Wisconsin lakes. J. Wisc. Acad. Sci. 68:90-96.

LeBlond, A., and Orvig, S. 1982. Une definition plus approprie de la thermocline lacustre saisonniere. Atmosphere Ocean 20:317-326.

Mortimer, C. H. 1974. Lake hydrodynamics. Int. Ver. Theor. Angew. Limnol. Verh. 20:124-197.

Panofsky, H. A., and Brier, G. W. 1968. Some application of statistics to meteorology. University Park, PA: Pennsylvania State University Press.

Patalas, K. 1984. Mid-summer mixing depths of lakes at different latitudes. Int. Ver. Theor. Angew. Limnol. Verh. 22:97-102.

Pennak, R. W. 1955. Comparative limnology of eight Colorado mountain lakes. Boulder, CO: University of Colorado Press.

Pollard, R. T., Rhines, P. B., and Thompson, R. O. R. Y. 1973. The deepening of the wind-mixed layer. Geophys. Fluid Dynam. 3:381-404.

Ragotzkie, R. A. 1978. Heat budgets in lakes. In Lakes: chemistry, geology and physics, ed. A. Lerman, pp. 1-19. New York: Springer-Verlag.

Reid, R. A., Locke, B., and Girard, R. 1983. Temperature profiles in the Muskoka-Haliburton study lakes (1976-1982). Data Report DR83/4, Ontario Ministry of the Environment; Water Resources Branch. Toronto, Ontario.

Simons, T. J. 1980. Circulation models of lakes and inland seas. Can. Bull. Fish. Aquat. Sci. 203.

Spigel, R. H., and Imberger, J. 1980. The classification of mixed layer dynamics in lakes of small-to mediumsize. J. Phys. Oceanogr. 10:1104-1121.

Yoshimura, S. 1936. A contribution to the knowledge of deep water temperatures of Japanese lakes (1) Summer temperature. Jap. J. Astr. Geophys. 13:61-120. 